\title{
Editorial
}

\section{Factors Affecting Pollinators and Pollination}

\author{
Zachary Y. Huang' ${ }^{1}$ and Tugrul Giray ${ }^{2}$ \\ ${ }^{1}$ Department of Entomology, Michigan State University, East Lansing, MI 48824, USA \\ ${ }^{2}$ Department of Biology, University of Puerto Rico, San Juan, PR 00931, USA
}

Correspondence should be addressed to Zachary Y. Huang, bees@msu.edu

Received 4 November 2012; Accepted 4 November 2012

Copyright ( 2012 Z. Y. Huang and T. Giray. This is an open access article distributed under the Creative Commons Attribution License, which permits unrestricted use, distribution, and reproduction in any medium, provided the original work is properly cited.

While it has been known for at least a decade that the colony numbers of the managed pollinator, the Western honey bee Apis mellifera, was on the decline, pollinator problem was not well publicized until the Colony Collapse Disorder (CCD) further ravaged the honey bee population in the United States [1]. In addition to honey bees, now it is known that bumble bees [2] and other pollinators [3] are also on the decline, perhaps due to combined effects of pesticide use and habitat destruction by Homo sapiens. While in the past the main focus has been on the honey bees, we felt that a special issue that includes other pollinators was warranted. Thus was born this special issue, highlighting various important challenges pollinators face.

Stress from Pathogen. The paper by S. L. Bushmann et al. determined if the prevalence of Nosema bombi infection was related to history of commercial bumble bee use. Previous studies suggested that bumble bee rearing facilities can spread parasites to local bumble bee populations, but it is not clear whether use of commercial bumble bees in the field may increase infection rate of a pathogen. The study did not find a higher infection rate of Nosema in wild bumblebees (Bombus $s p p$.) sampled in lowbush blueberry fields with a history of commercial bumblebee use, compared to those without such a history. However, the study shows for sure one species of bumble bee, $B$. terricola, declined in sampled regions. This was most likely due to Nosema infection because about half of the bees were infected. However, it could also be due to other factors that first weakened the immune system of the host bees, then causing a higher rate of infection contributing to the population decline. These factors could be due to suboptimal habitats or pesticides used in the crops (blueberry) that end up in the nectar or pollen that these bees foraged upon. Future studies are needed to determine why this native species suffered such a high rate of infection.

Stress from Transportation. There are specific stressors only experienced by managed pollinators. Case in point, each year, over one million managed honey bee colonies are moved across the United States to California for almond pollination. Imagine being transported across three time zones in a highly crowded environment with poor ventilation-it does not sound healthy. Yet, we understand little about how transportation affects honey bee physiology or behavior. K. Ahn et al. conducted an extensive study with three trials in three different states (California, Georgia, and Michigan) to determine the effects of long distance transportation on honey bee physiology. They used a common source of bees, age-marked them by painting, then split them into two colonies, one experiencing transportation and one being stationary. They measured juvenile hormone titers, reasoning that transported bees will experience more stress, higher mortality of older bees, and thus young bees should develop faster to become foragers. Foragers would have higher juvenile hormone titers. Yet, they found no significant differences in juvenile hormone titers between bees reared in the two types of colonies. Protein content in head or thorax and lipid content in abdomen were also largely not different. The only constant measurement that responded to transportation seems to be the size of the food glands, the hypopharyngeal glands. This gland produces the protein portion of royal jelly or worker jelly, which also has lipid component secreted by mandibular glands. This study suggests that bees experiencing transportation have trouble fully developing their food glands, and this might affect their ability to nurse the next generation of workers. 
It would be interesting to determine the lasting effects of this transportation stress: do bees recover at all from such an effect? If so, how much time is needed?

Stress from Climate Change. Climate change is a rather large topic currently, but how climate change would affect pollinators remains unknown. D. L. Delgado et al. presented a model study to tackle this question for honey bees. The authors asked two questions for Puerto Rico. First, what is the relationship between honey yield and climate? Second, what is the extent of its spatial variability under current and future scenarios of climate change? The authors developed a number of bioclimatic models that were used in a geographical information system to identify suitable areas for honey production under current and future scenarios of climate change. Models indicated importance of three bioclimatic variables: (1) temperature seasonality, (2) mean temperature of the wettest quarter negatively correlated with honey yields, and (3) precipitation of the wettest month positively correlated with honey yields. In general, the models showed that both honey yields and areas suitable for honey production will decrease under scenarios of climate change. These results illustrate the possible impacts of climate change on honey bees and a method for investigating impact of environmental factors on pollinators.

Plant-Pollinator Interactions. It is known that both biotic and abiotic factors can affect soil quality, which in turn can significantly impact plant growth, productivity, and resistance to pests. Y. J. Cardoza et al., therefore, examined whether soil enhancements of vermicompost (earthworm compost) affected the behavior and physiology of a bumble bee species Bombus impatiens. Soil enhancement seems positive for pollinators because it significantly increased the bees' visit durations and reduced time to first discovery of flowers. Bumblebee workers that had fed on flowers from plants grown on enhanced soil also possessed significantly larger and more active ovaries, suggesting a better nutrition of these flowers to bees. Indeed, pollen from these plants had significantly higher protein content, although sugar content from nectar was higher but not significant. It would be interesting to pursue further what nutrients are enriched in these vermicompost added soils.

Plant-pollinator interactions are often considered as tightly coevolved, mutualistic relationships. However, not all visitors may be efficient pollinators. R. W. M. U. M. Wanigasekara and W. A. I. P. Karunaratne studied the bees visiting flowers of the vegetable crop, Solanum violaceum, and the efficiency of buzz pollination by bees on fruit and seed production in Sri Lanka. Four buzzing bee species: Hoplonomia westwoodi, Amegilla comberi, Patellapis kaluterae, and Xylocopa tenuiscapa, and 3 nonbuzzing species: Apis dorsata, Trigona iridipennis, and Ceratina hieroglyphica visited the flowers of S. violaceum. Buzzing bees were the first to visit Solanum flowers and were followed by nonbuzzing bees. Handling time of $H$. westwoodi and $P$. kaluterae varied with the availability of pollen in anthers that deplete with the age of flower and stayed longer at new flowers than at old flowers. Handling time of the larger buzzing bee, $H$. westwoodi, was higher than that of the smaller P. kaluterae. The fruit set, seed set, and seed germination ability in flowers visited by buzzing bees were significantly higher than those of the flowers bagged to exclude pollinators.

The work on potential pollinators or floral visitors to Brazil nut in the central Amazon rainforest could be a classic because of careful observation and description first being reported in this issue (M. C. Cavalcante et al.). This study is similar to the study by Wanigasekara and Karunaratne which studied bee visitors of one plant species, Solanum, but was carried out with cultivated Brazil nut trees (Bertholletia excelsa Bonpl., Lecythidaceae) in the Central Amazon rainforest, Brazil. The study aimed to determine pollination requirements and floral visitors of Brazil nut trees and to investigate foraging behavior of these visitors in commercial plantations. Results showed that B. excelsa was predominantly allogamous but capable of setting fruits by geitonogamy. Nineteen bee species, belonging to two families, visited and collected nectar and/or pollen throughout the day. Individuals from 16 of 19 bee species succeeded entering the flower and potentially acted as pollinators. However, after considering abundance, flower frequency, and foraging behavior of floral visitors, it was concluded that only two species, Eulaema mocsaryi and Xylocopa frontalis, could be, considered relevant potential pollinators.

Invasive Species. Invasive species also take part in plantpollinator interactions. The "tour-de-force" study of pollinators of invasive and native species of Potentilla by J. McIver and K. Erickson demonstrates how invasive plants and invasive pollinators could augment the risk to native species. In other words, interactions of invasive species in a region should be considered and not just each invasive species on its own accord! The authors studied four sites in northeastern Oregon, USA in a relatively long-term study (2002 to 2004), and found that invasive plant sulfur cinquefoil and its native congener slender cinquefoil attracted over 100 insect species in 4 orders. Interestingly, compared to the native, nearly twice as many seeds germinated for sulfur cinquefoil, with seeds germinating over a longer period of time. The greater frequency of nonnative pollinators such as honey bees was observed on the invasive Potentilla species.

As the subtitle of this special issue indicates, by its nature, studying pollinators requires combining many different fields of expertise such as taxonomy, physiology, behavior, and others. We would like to thank all contributors, many reviewers from diverse fields, and all authors who submitted their work for this issue. Pollination has a great impact on life on earth, and we do hope that this special issue would be a beginning to combine basic and applied studies to expand our knowledge on pollinator biology.

\section{Zachary Y. Huang Tugrul Giray}

\section{References}

[1] D. L. Cox-Foster, S. Conlan, E. C. Holmes et al., "A metagenomic survey of microbes in honey bee colony collapse disorder," Science, vol. 318, no. 5848, pp. 283-287, 2007. 
[2] S. A. Cameron, J. D. Lozier, J. P. Strange et al., "Patterns of widespread decline in North American bumble bees," Proceedings of the National Academy of Sciences of the United States of America, vol. 108, no. 2, pp. 662-667, 2011.

[3] S. Kluser and P. Peduzzi, Global Pollinator Decline: A literature Review, UNEP/GRIDEurope, 2007. 

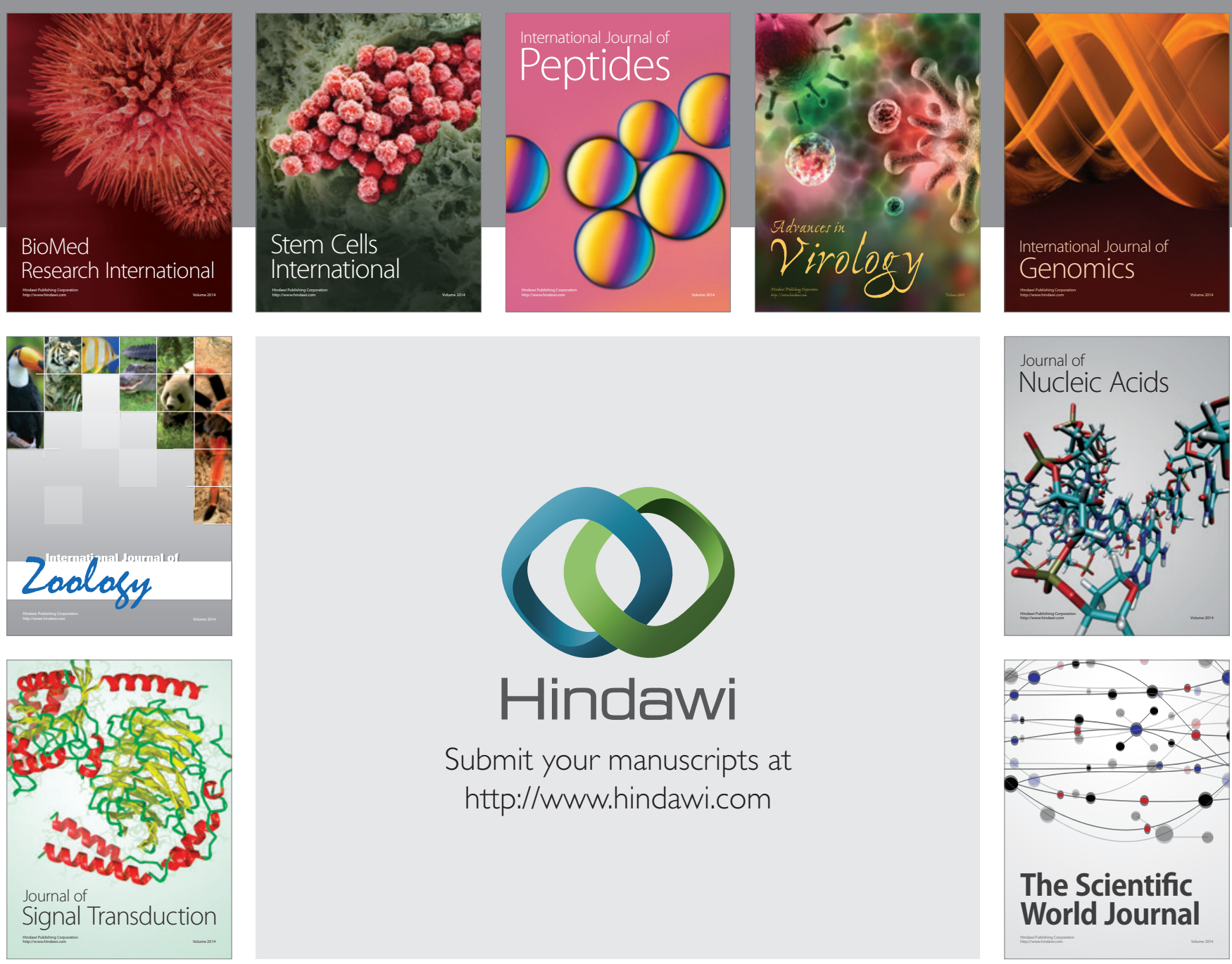

Submit your manuscripts at

http://www.hindawi.com
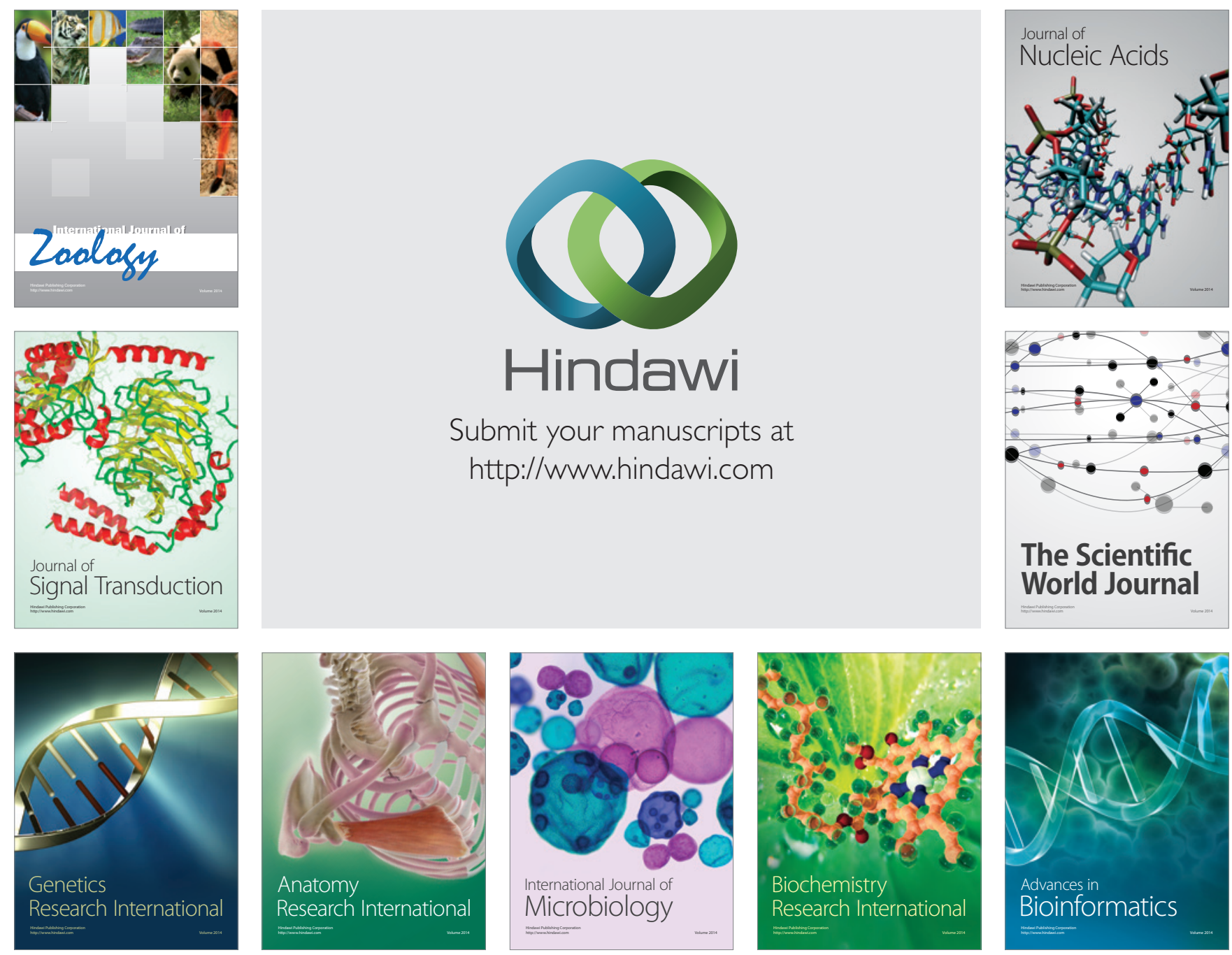

The Scientific World Journal
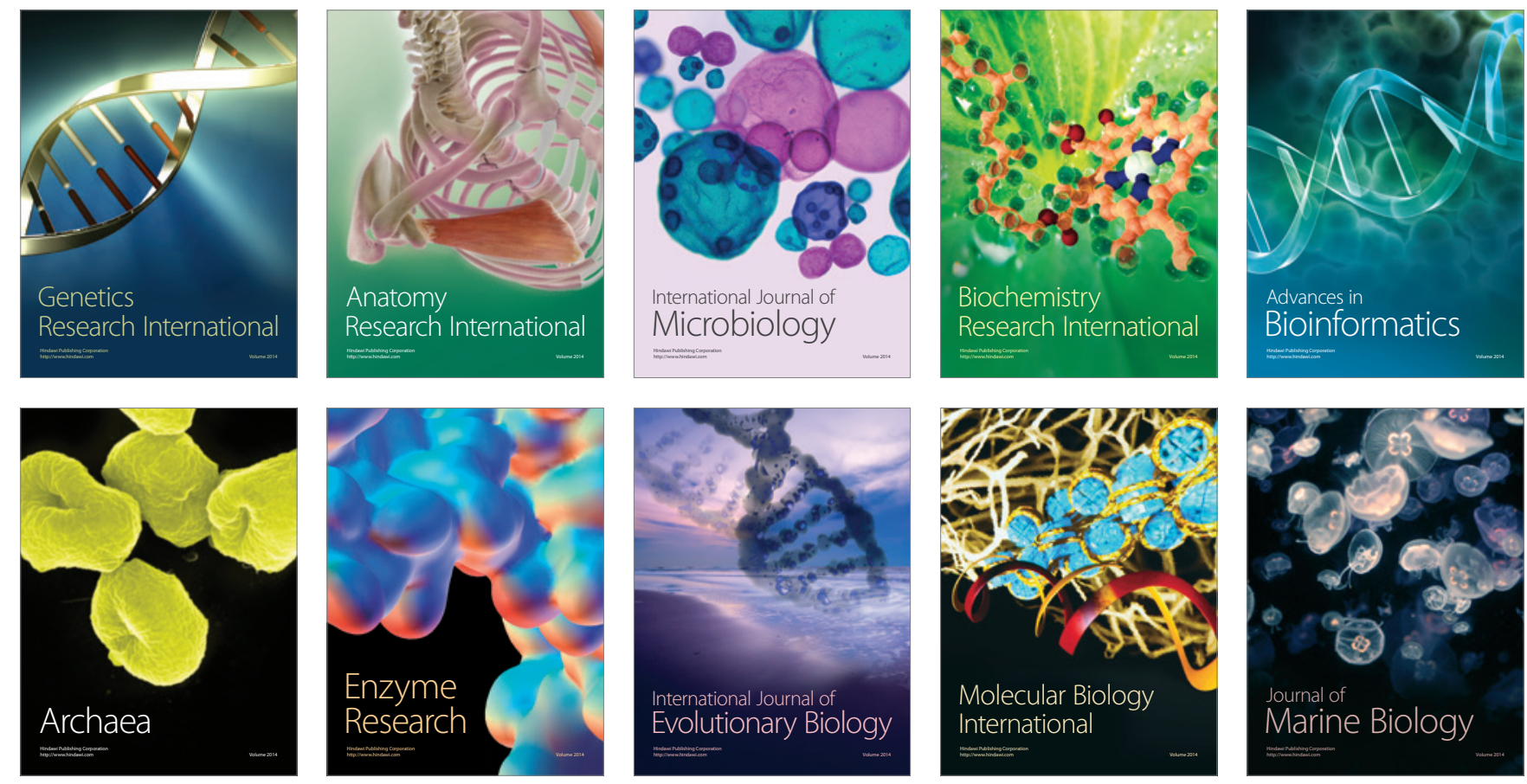